ScIDice

\section{Gingival Retraction Methods Used In Different Gingival Biotypes As Classified By Anon Ross And Seibert And Lindhe Classification}

Research Article

Asha. S. Hariharan ${ }^{1}$, Subhashree $\mathrm{R}^{2 *}$, Rakshagan $\mathrm{V}^{3}$

${ }^{1}$ Saveetha Dental College and Hospital, Saveetha Institute of Medical and Technical Sciences, Saveetha University, 162, Poonamallee High Road, Chennai-600077, Tamil Nadu, India.

${ }^{2}$ Senior Lecturer, Department of Prosthodontics, Saveetha Dental College and Hospital, Saveetha Institute of Medical and Technical Sciences, Saveetha University, 162, Poonamallee High Road, Chennai-600077, Tamil Nadu, India.

${ }^{3}$ Senior Lecturer, Department of Prosthodontics, Saveetha Dental College and Hospital, Saveetha Institute of Medical and Technical Sciences, Saveetha University, 162, Poonamallee High Road, Chennai-600077, Tamil Nadu, India.

\title{
Abstract
}

To access the prevalence of the gingival biotype as classified by Anon Ross and Seibert and Lindhe classification and to evaluate its correlations with the mode of mechanical retraction employed. 200 case sheets of patients who visited SDC with a requirement of fabrication of a fixed dental prosthesis were obtained from DIAS and evaluated. The gingival biotype of the patients were assessed and classified under the Anon Ross and Siebert and Lindhe classification and the mode of retraction used for the case was also noted. Results obtained were tabulated using an excel sheet. Descriptive statistics was performed to assess the prevalence and correlation was assessed using chi square test.The prevalence of "Scalloped and thin " according to Anon and Ross and "thin " according to Seibert and Lindhe were 55.5\% and 54.1\% respectively. Similarly for "flat and thick" and "thick" the prevalence was $44 \%$ and $45 \%$ of total sample size. There is a statistically significant association between the mechanical retraction method used in both the gingival biotypes. Gingival health is of paramount importance. The mechanical retraction method used should be in accordance with the gingival biotypes to prevent unwarranted trauma to the gingiva. This necessitates the need for a protocol to use a particular retraction method based on gingival biotypes.

Keywords: Anon Ross Classification; Gingival Biotype; Gingival Retraction; Seibert-Lindhe Classification.

\section{Introduction}

The clinical success and longevity of any prosthetic restoration is dependent on accurate recording of the surface that receives the restoration [1-4]. In terms of the dental crowns the relationship between the health of the periodontium and the restoration of the teeth is inseparable [5-8]. As much as it is necessary to record the prepped tooth surface and the finish lines; it is equally important to maintain the health of the periodontium [9-11]. Hence before attempting to perform any gingival displacement technique in the process of impression making, it is important to assess the periodontal health of the tooth or teeth involved [12-14]. There are three major steps involved in the examination of the periodontium which includes [15].
1. Periapical/ Bitewing to assess crestal bone level .

2. Visual examination - color, contour, consistency, position, surface, texture.

3. Sulcus depth measurement.

Before choosing a displacement technique it is also important to evaluate the biotype of the gingival to be manipulated. The types of gingival biotypes were first described by Oschsenbien and Ross in 1969 into "Scalloped and thin" and "flat and thick" [16]. This was followed by Seibert and Lindhe who classified them as "Thick" which was > or equal to $2 \mathrm{~mm}$ thickness and "Thin", greater or equal to $1.5 \mathrm{~mm}$ thickness $[17,18]$. The "Thick and Flat" biotype consists of greater amounts of fibrous tissue [19]. They are better resistant due to underlying bone. The "Scalloped and thin" biotype is thin friable with limited masticatory mucosa and

Subhashree R,

Senior Lecturer, Department of Prosthodontics, Saveetha Dental College and Hospital, Saveetha Institute of Medical and Technical Sciences, Saveetha University, 162, Poonamallee High Road, Chennai-600077, Tamil Nadu, India.

E-mail: Subhashreer.sdc@saveetha.com

Received: November 10, 2020

Accepted: December 15, 2020

Published: December 18, 2020

Citation: Asha. S. Hariharan, Subhashree R, Rakshagan V. Gingival Retraction Methods Used In Different Gingival Biotypes As Classified By Anon Ross And Seibert And Lindhe Classification. Int J Dentistry Oral Sci. 2020;7(12):1298-1301. doi: http://dx.doi.org/10.19070/2377-8075-20000257

Copyright: Subhashree $\mathbf{R}^{\circ} 2020$. This is an open-access article distributed under the terms of the Creative Commons Attribution License, which permits unrestricted use, distribution and reproduction in any medium, provided the original author and source are credited. 
trauma to the gingiva could lead to inflammation and development of black triangles.

The most commonly used mechanical tissue displacement technique includes the single or double cord technique [20]. The double cord technique though takes additional time and could induce trauma; it comes handy when the finish line is subgingival. The cords used for a gingival sulcus should be such that the induced trauma should be reversible. Works of authors such as Wassell et al., [21] and Clyde S et al., [14] dictate the protocol of use of the double cord technique.

There is numerous literature individually on the biotype of gingival tissue such as the works of Sanavi F et al., [22], RG Shiva Manjunath et al., [23], and similar works on the different gingival retraction methods. But there is a sheer lack of studies describing a relation between the gingival biotype and the size of the cord that was used.

This study hence aims to assess the prevalence of the biotype of gingiva and to correlate the kind of mechanical retraction employed.

\section{Material And Method}

The study was designed to be a retrospective strictly; based on patient data. The study was conducted in Saveetha Dental College, Chennai during the period of March 2019 to March 2020.

200 case sheets were randomly selected from among the patients who had undergone fabrication of fixed dental prosthesis.

The case sheets were obtained from the institution's record maintenance system (DIAS) which maintains all the patient related information, records of treatment done and the patient photographs.

The gingival biotype of the patient's gingiva was recorded under two classification systems; Aron and Ross, and Seibert and Lindhe.

Following this, the details of mechanical retraction of gingiva was obtained. This included the combination of cords used in gingival retraction.
The obtained data was tabulated using Excel sheets and statistical analysis was performed using SPSS software version [23].

Descriptive analysis was done to assess the frequency and percentage of distribution. Followed by this the correlation between the combination of mechanical retraction was done against the gingival biotype using Chi square test.

\section{Results And Discussion}

The frequency distribution of gingival biotype showed the following results (Table 1);

The thinner gingival biotypes falling under "Scalloped and thin" in Anon Ross and "thin" were marginally more prevalent; 55.8\% and $54.3 \%$ respectively as compared to the thicker biotypes of gingiva.There was increased association between thick biotype gingiva and the use of the combination of a 00 size and a 1 size cord. Similarly for the thin gingival biotype the use of combination of a 000 size with 1 size cord was more prevalent. The correlation between the gingival retraction method and the gingival biotype was also significant with $\mathrm{p}=0.006$ for Anon Ross classification and $\mathrm{p}=0.002$ for Seibert and Lindhe classification.

The current study evaluated the prevalence of the commonly occurring gingival biotypes in patients undergoing fabrication of fixed partial denture. The measured prevalence was based on the Anon- Ross and Seibert- Lindhe classification. The gingival biotype classifications are not limited to these, and the other classifications which are related to this includes; classifications by Becker et al [24] and De Rouck et al., [25-27].

The prevalence of both the thick and thin variant was in a similar range, negating the possible error in the evaluation. Similar studies on prevalence of gingival biotype was done by $\mathrm{KH}$ Zawawi et al [28]; R shah et al., [29] and many other authors [30, 31].

The method of gingival retraction employed has direct influence on the gingival tissues. Gingival retraction may be mechanical, chemical or mechano-chemical. The combination of mechanical and chemical can lead to varying degrees of stripping or necrosis of the gingival sulcus32. Mechanical retraction done with the application of proper techniques is unlikely to cause serious injury to the sulcus. The studies performed by Ameroth G; and Harrison $\mathrm{J}$ are testaments to the fact [33].

Table 1. Depicting the frequency distribution of retraction method with respect to the gingival biotype; frequency distribution of the gingival biotypes; Chi-square and $\mathrm{p}$ value of association. The table shows that the thinner biotypes are marginally more prevalent than the thicker biotypes, and there exists a statistically significant association between gingival biotype and the choice of cords for mechanical retraction.

\begin{tabular}{|c|c|c|c|c|c|c|}
\hline \multirow[b]{2}{*}{ Gingival Biotype } & \multicolumn{3}{|c|}{ Gingival Retraction Method } & \multirow{2}{*}{$\begin{array}{l}\text { Frequency } \\
\text { Distribution }\end{array}$} & \multirow{2}{*}{$\begin{array}{l}\text { Chi- } \\
\text { square }\end{array}$} & \multirow[b]{2}{*}{ P value } \\
\hline & $\begin{array}{l}2 \text { Cords } \\
(000+1)\end{array}$ & $\begin{array}{c}2 \text { Cords } \\
(00+1)\end{array}$ & $\begin{array}{c}2 \text { Cords } \\
(0+1)\end{array}$ & & & \\
\hline Anon Ross Flat\&Thick & $26.10 \%$ & $60.20 \%$ & $13.60 \%$ & $44.20 \%$ & \multirow{2}{*}{10.208} & \multirow{2}{*}{0.006} \\
\hline Scalloped \& Thin & $47.70 \%$ & $45.00 \%$ & $7.20 \%$ & $55.80 \%$ & & \\
\hline Seibert \& Lindhe Thick & $23.30 \%$ & $65.50 \%$ & $11.10 \%$ & $45.20 \%$ & \multirow{2}{*}{16.775} & \multirow{2}{*}{0.002} \\
\hline Thin & $50.10 \%$ & $40.70 \%$ & $9.20 \%$ & $54.30 \%$ & & \\
\hline
\end{tabular}


Figure 1. Bar graph shows the association between gingival biotype classified by Seibert Lindhe classification (X-axis) and percentage distribution of the gingival retraction methods (Y-axis). The most commonly used combination of cords for mechanical retraction among Thick gingival biotypes is the 2 Cords $(00+1)$ (Green) and for thin biotypes it is 2 Cords $(000+1)$ (Blue). Chi-square value-16.775; p - 0.002; hence statistically significant.

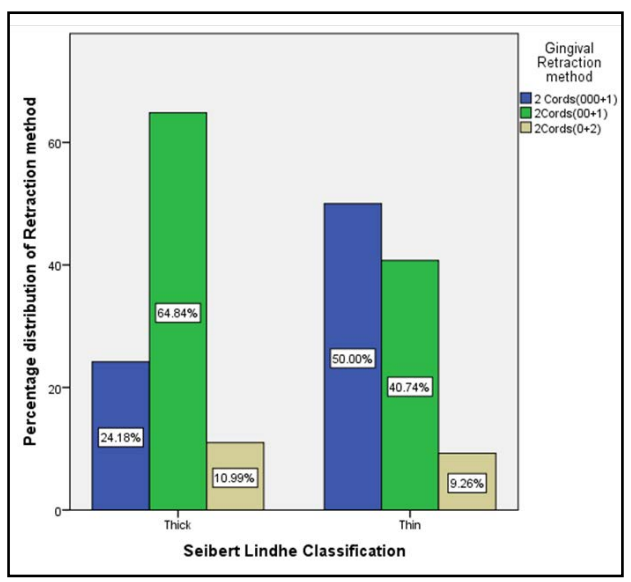

Figure 2. Bar graph shows the association between gingival biotype classified by Anon Ross classification (X-axis) and the percentage distribution of the gingival retraction methods (Y-axis).

For the Scalloped and Thin biotype 2 Cords $(000+1)$ (blue) was commonly used, and for Flat and thick 2 Cords $(00+1)$ (Green) was commonly used. Chi-square-10.208; p value - 0.006; hence statistically significant.

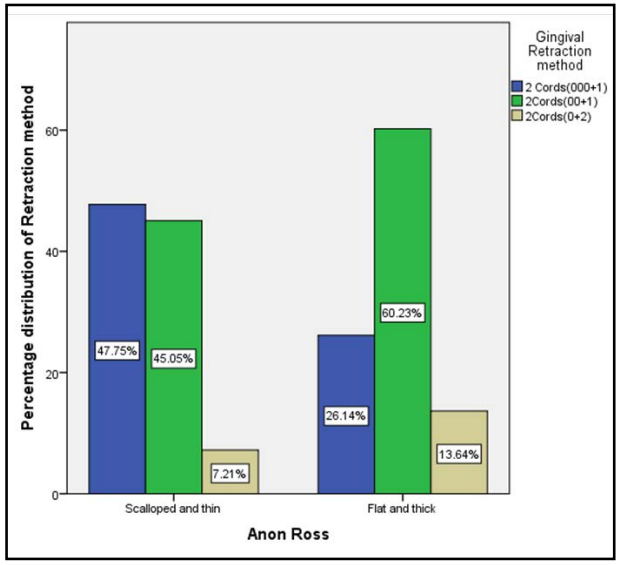

The current study made use of a combination of two threads, one being smaller than the other. The smaller thread functions to prevent hemorrhage and seepage from the gingival sulcus.the larger cord is placed above this to displace the gingival tissue away from the margin. Study performed by Hansen et al showed the prevalence of choice for the two cord impression technique over the other [34]. Three combinations of cords were used in this study; $(000+1)(00+1)$ and $(0+1)$. The result of the study revealed that the combination $(00+1)$ was commonly used. There was a statistically significant relation between the method of mechanical retraction and the gingival biotype. This signified the correct usage of combinations of cords for a particular gingival biotype. The current study compared only the prevalence of mechanical retraction methods and correlated it with the gingival biotype. Evaluation of different types of retraction methods; will yield a more comprehensive result and would provide more options for the practitioners. Study done on a large scale; with data from different centres could bring in more and varied information regarding the scenarios of gingival retraction.

Gingival retraction is an important aspect of impression making and plays a vital role in dividing its quality [30-33]. Further research, incorporating the elements of pressure exerted by the cord and the tissue retraction of the gingiva to this pressure could be correlated with the selection of method of retraction. This could also enable us to lay down a protocol with standardised techniques for retraction based on gingival biotypes.

\section{Conclusion}

As observed from the current study, the thinner gingival biotypes as classified by both Seibert and Lindhe and Anon Ross classification were marginally more prevalent than the thicker biotypes. There was a significant association with the choice of cords used in mechanical retraction in terms with the gingival biotypes. A combination of $000+1$ size cords were used in thinner gingival biotypes and $00+1$ were used in thicker biotypes. Careful examination of gingival biotype is necessary for appropriate treatment planning and also in monitoring the outcome measures.Use of the correct method of gingival retractions could guarantee an accurate impression and a better fitting prosthesis. Further research on this will only improve the existing protocol and thus be encouraged.

\section{Acknowledgement}

We would like to acknowledge Saveetha dental college and hos- 
pital for providing complete patient details required for the study purpose and their constant help and support for this research.

\section{References}

[1]. Khan MW. An overview of dental impression disinfection techniques-A literature review. JPDA. 2018 Oct;27(04):208.

[2]. Ranganathan H, Ganapathy DM, Jain AR. Cervical and Incisal Marginal Discrepancy in Ceramic Laminate Veneering Materials: A SEM Analysis. Contemp Clin Dent. 2017 Apr-Jun;8(2):272-278. PMID: 28839415.

[3]. Jain AR, Dhanraj M. A clinical review of spacer design for conventional complete denture. Biology and Medicine. 2016;8(5):1.

[4]. Ashok V, Nallaswamy D, Benazir Begum S, Nesappan T. Lip Bumper Prosthesis for an Acromegaly Patient: A Clinical Report. J Indian Prosthodont Soc. 2014 Dec; 14(Suppl 1):279-82. PMID: 26199531.

[5]. Ashri NY, AlRifaiy MQ, El Metwally A. The effect of gingival retraction cord on periodontal health compared to other gingival retraction procedures: A systematic review. Periodontics Prosthodont. 2016; 3.

[6]. Den Subasree S, Murthykumar K. Effect of aloe vera in oral health-A review. Research Journal of Pharmacy and Technology. 2016 May 1; 9(5): 609.

[7]. Harshitha C, Murthykumar K, Deepak A. Beneficial Effects of Olive Oil on Human Health-A Review. Research Journal of Pharmacy and Technology. 2016 May 1; 9(5): 593.

[8]. Den Basha FY, Ganapathy D, Venugopalan S. Oral hygiene status among pregnant women. Research Journal of Pharmacy and Technology. $2018 \mathrm{Jul}$ 31;11(7):3099-102.

[9]. Jyothi S, Robin PK, Ganapathy D. Periodontal health status of three different groups wearing temporary partial denture. Research Journal of Pharmacy and Technology. 2017 Dec 1;10(12):4339-42.

[10]. Vijayalakshmi B, Ganapathy D. Medical management of cellulitis. Research Journal of Pharmacy and Technology. 2016 Nov 28;9(11):2067-70.

[11]. Kumar SB, Dhanraj M. Role of Vitamin C in body health. Research Journal of Pharmacy and Technology. 2018 Apr 1;11(4):1378-80.

[12]. Wilson RD, Maynard G. Intracrevicular restorative dentistry. Int J Periodontics Restorative Dent. 1981;1(4):34-49. PMID: 7047430.

[13]. Ganapathy D, Sathyamoorthy A, Ranganathan H, Murthykumar K. Effect of Resin Bonded Luting Agents Influencing Marginal Discrepancy in All Ceramic Complete Veneer Crowns. J Clin Diagn Res. 2016 Dec; 10(12): ZC67-ZC70. PMID: 28209008.

[14]. Dhanraj D, Dhanraj. Effect of Marginal Discrepancy induced by CAD/ CAM and Conventional Ceramic Processing Techniques in All Ceramic Complete Veneer Retainers - A Systematic Review. 2014; 13: 74-85.

[15]. Prasad KD, Hegde C, Agrawal G, Shetty M. Gingival displacement in prosthodontics: A critical review of existing methods. Journal of interdisciplinary dentistry. 2011 Jul 1;1(2):80.

[16]. Ochsenbein C. Current status of osseous surgery. J Periodontol. 1977 Sep; 48(9): 577-86. PMID: 333091

[17]. Claffey N, Shanley D. Relationship of gingival thickness and bleeding to loss of probing attachment in shallow sites following nonsurgical periodontal therapy. J Clin Periodontol. 1986 Aug; 13(7): 654-7. PMID: 3531244.

[18]. Lindhe J. Prevention and Therapy of Periodontal Disease: Present Knowl- edge of the Effect of Prevention and Therapy of Periodontal Disease. Journal of Clinical Periodontology. 1980 Aug; $7(4): 331$.

[19]. Bandi R, Shetty T, Rodrigues SJ, Mundathaje M, Saldanha S, Hegde P. Comparison of Quality of Impression and Clinical Performance after Gingival Displacement with Magic Foam Cord and Gingival Retraction Cord-An in vivo Study. Indian Journal of Public Health Research \& Development. 2018 Aug $1 ; 9(8)$.

[20]. Cloyd S, Puri S. Using the double-cord packing technique of tissue retraction for making crown impressions. Dent Today. 1999 Jan;18(1):54-9. PMID: 10765795.

[21]. Wassell RW, Barker D, Walls AW. Crowns and other extra-coronal restorations: impression materials and technique. Br Dent J. 2002 Jun 29; 192(12): 679-84. PMID: 12125794.

[22]. Sanavi F, Weisgold AS, Rose LF. Biologic width and its relation to periodontal biotypes. J Esthet Dent. 1998; 10(3): 157-63. PMID: 9759032.

[23]. Manjunath RG, Rana A, Sarkar A. Gingival Biotype Assessment in a Healthy Periodontium: Transgingival Probing Method. J Clin Diagn Res. 2015 May; 9(5): ZC66-9. PMID: 26155566.

[24]. Becker W, Ochsenbein C, Tibbetts L, Becker BE. Alveolar bone anatomic profiles as measured from dry skulls. Clinical ramifications. J Clin Periodontol. 1997 Oct; 24(10): 727-31. PMID: 9350556.

[25]. De Rouck T, Eghbali R, Collys K, De Bruyn H, Cosyn J. The gingival biotype revisited: transparency of the periodontal probe through the gingival margin as a method to discriminate thin from thick gingiva. J Clin Periodontol. 2009 May; 36(5): 428-33. PMID: 19419444.

[26]. Selvan SR, Ganapathy D. Efficacy of fifth generation cephalosporins against methicillin-resistant Staphylococcus aureus-A review. Research Journal of Pharmacy and Technology. 2016 Oct 28;9(10):1815-8.

[27]. Duraisamy R, Krishnan CS, Ramasubramanian H, Sampathkumar J, Mariappan S, Navarasampatti Sivaprakasam A. Compatibility of Nonoriginal Abutments With Implants: Evaluation of Microgap at the Implant-Abutment Interface, With Original and Nonoriginal Abutments. Implant Dent. 2019 Jun; 28(3): 289-295. PMID: 31124826.

[28]. Zawawi KH, Al-Harthi SM, Al-Zahrani MS. Prevalence of gingival biotype and its relationship to dental malocclusion. Saudi Med J. 2012 Jun; 33(6): 671-5. PMID: 22729124.

[29]. Shah R, Sowmya NK, Mehta DS. Prevalence of gingival biotype and its relationship to clinical parameters. Contemp Clin Dent. 2015 Sep; 6(Suppl 1): S167-71. PMID: 26604569.

[30]. Jain AR, Nallaswamy D, Ariga P, Ganapathy DM. Determination of correlation of width of maxillary anterior teeth using extraoral and intraoral factors in Indian population: A systematic review. World J Dent. 2018 Jan; 9:68-75.

[31]. Venugopalan S, Ariga P, Aggarwal P, Viswanath A. Magnetically retained silicone facial prosthesis. Niger J Clin Pract. 2014 Mar-Apr; 17(2):260-4. PMID: 24553044.

[32]. Zetterqvist L, Anneroth G, Nordenram A. Glass-ionomer cement as retrograde filling material. An experimental investigation in monkeys. Int J Oral Maxillofac Surg. 1987 Aug;16(4):459-64. PMID: 3117920.

[33]. Harrison JD. Effect of retraction materials on the gingival sulcus epithelium. The Journal of Prosthetic Dentistry. 1961 May 1;11(3):514-21.

[34]. Hansen PA, Tira DE, Barlow J. Current methods of finish-line exposure by practicing prosthodontists. J Prosthodont. 1999 Sep; 8(3): 163-70. PMID: 10740498 . 